\title{
Factors contributing to the occurrence of cancer metastasis to brain
}

\author{
Authors \\ T.N.Vijayasree ${ }^{1}$, Vidhya Narasimhan ${ }^{1 *}$, R. Mohan Kumar ${ }^{2}$, M.Mohamed Ibrahim ${ }^{1}$ \\ ${ }^{1}$ Kilpauk Medical College, Chennai, India \\ ${ }^{2}$ Directorate of Public Health and Preventive Medicine, Chennai, India \\ Attributed to: Radiation Oncology Department, Government Royapettah Hospital, Kilpauk Medical College, \\ Chennai \\ *Corresponding Author \\ Vidhya Narasimhan \\ Mailing address: F3, Kanakadhara Tiruvengadam, 7/3, Cart track road, T Nagar, Chennai, India, 600017
}

\begin{abstract}
In a cancer patient when there is metastasis to brain the prognosis becomes very poor. But only some patients get metastasis to brain. In this study, in patients with brain metastasis, the demographic profile, the site of primary tumour, stage at diagnosis, histopathology, immunohistochemistry and extent of dissemination, have been analysed to throw light on susceptibility to metastasis brain. 35 patients with brain metastasis treated in a period of 5 years were studied retrospectively. $40 \%$ of the patients were young (age group 31- 45 years) and $50 \%$ presented with only headache. There was strong association between occurrence of multiple metastasis brain (against single lesion brain) and visceral /bone spread. Breast was the most common primary site in the whole group while lung was commoner in exclusive brain metastasis subset and patients in stage four at initial presentation itself. This signifies the need for screening for lung malignancy in the high risk group to detect at an earlier stage. Lung cancer patients have 4 times more chance of having brain metastasis with no visceral or bone metastasis. In breast cancer $17 \%$ patients have exclusive brain metastasis. In 2 patients PET CT detected asymptomatic metastatic lesions brain.
\end{abstract}

Keywords: Metastasis brain, Secondaries brain.

\section{Introduction}

In spite of all advancements in the field of neurosurgery and oncology, the prognosis of patients with brain metastasis remains dismal. Among these patients, the prognosis is not uniform and varies depending on the site and stage of primary, patients' neurologic status, and on how much disseminated the disease is. Thus, the management has to be individualised. A detailed study of various parameters that have impact on the management and prognosis, may help us modify and individualise treatment plans.

\section{Operational Definition}

Brain metastasis: Newly detected cases of space occupying lesions brain with radiological features highly suggestive of metastasis brain, with malignancy proven by histopathology from primary site or the most accessible secondary site.

Progression free survival (PFS): The time period from the detection of malignancy to the detection of metastasis. 


\section{Objectives}

- To describe demographic profile, histopathological and immuno-histochemical features of patients with brain metastasis

- To analyse the factors determining occurrence of metastasis to brain from primaries elsewhere

\section{Methods}

Study Title- Factors contributing to the occurrence of cancer metastasis to brain

Study Setting- Government Royapettah Hospital, Kilpauk Medical College, Chennai, India

Study Sample- Newly detected metastasis brain patients

Study Duration- Diagnosis of metastasis brain between October 2013 to September 2018.

Material and Method- Data extraction from the hospital records with pre-designed data extraction Form

Study Design- Retrospective cross-sectional study

Sample Size- 35 (All the patients satisfying the case definition in the reference period were included in the study)

\section{Inclusion Criteria}

All patients who were identified with brain metastasis at Department of radiation oncology, Government Royapettah hospital, attached to Kilpauk medical college, from 2013 October to 2018 September, for a period of five years were studied retrospectively.

\section{Exclusion Criteria}

- Patients with Non-brain metastasis alone

- Patients undergoing radiotherapy for primary tumours brain

\section{Results}

Out of 35 patients included in the study, majority $(26,74 \%)$ were female. $31-45$ years $(14,40 \%)$ was the most common age group followed by $46-$ 60 years $(9,26 \%)$. The commonest presenting symptom was headache $(17,50 \%)$. All 3 patients with hemiparesis and 6 patients with seizures had perilesional oedema (Table 1).
Table 1: Demography and clinical presentation of patients admitted with brain metastasis in Radiation Oncology Department, Royapettah hospital, Kilpauk Medical College, Chennai 201318

\begin{tabular}{|c|c|c|c|}
\hline Category & Description & $\#$ & $\%$ \\
\hline \multirow{4}{*}{ Age Group } & Up to $30 \mathrm{yrs}$ & 3 & 8 \\
\hline & 31 to 45 & 14 & 40 \\
\hline & 46 to 60 & 9 & 26 \\
\hline & More than 60 & 9 & 26 \\
\hline \multirow{2}{*}{ Sex } & Male & 9 & 26 \\
\hline & Female & 26 & 74 \\
\hline \multirow{4}{*}{ Primary Site } & Breast & 18 & 51 \\
\hline & Lung & 12 & 34 \\
\hline & Cervix / Ovary & 3 & 9 \\
\hline & Others & 2 & 6 \\
\hline \multirow{2}{*}{$\begin{array}{l}\text { Metastasis } \\
\text { Site }\end{array}$} & Supratentorial & 27 & 77 \\
\hline & Infratentorial & 8 & 23 \\
\hline \multirow{3}{*}{$\begin{array}{l}\text { Metastasis } \\
\text { number }\end{array}$} & One & 17 & 49 \\
\hline & Two & 3 & 8 \\
\hline & Multiple & 15 & 43 \\
\hline \multirow{2}{*}{ Oedema } & Yes & 30 & 86 \\
\hline & No & 5 & 14 \\
\hline \multirow{2}{*}{$\begin{array}{l}\text { Neurological } \\
\text { Deficit }\end{array}$} & Yes & 13 & 37 \\
\hline & No & 22 & 63 \\
\hline
\end{tabular}

Two of 35 patients were asymptomatic for brain metastasis, and lesions were detected incidentally by PET scan. Both had primary lesion in lung with disseminated metastasis, visceral and brain, at first evaluation itself.

Radiologically 17(49\%) patients had single lesion brain with almost equinumerous $(15,43 \%)$ having multiple lesions and $3(8 \%)$ patients had 2 lesions brain. Majority $(25,71 \%)$ of patients had supratentorial lesions (cerebral cortex) while $5(14 \%)$ had lesions in cerebellum, 4 in both and 1 in clivus. $9(26 \%)$ patients had parietal lobe lesions and 7 patients had frontal lesions. 86\% (30) had radiological evidence of perilesional oedema.

Of 15 patients, with multiple brain metastasis, 11 (73\%) had other visceral metastasis, in contrast to $6(30 \%)$ out of 20 patients with 1 or 2 brain metastases. To the corollary, among 17 brain metastasis cases with visceral spread, $11(65 \%)$ had multiple lesions brain whereas out of 18 brain metastasis cases with no visceral spread, 14 (78\%) had 1 or 2 lesions brain. Compared to patients 
with 1 or 2 metastatic lesions brain, the patients with multiple lesions brain have 6 times more chance of having disseminated disease in the form of additional visceral/bone metastasis (odds ratio $=6.04, \mathrm{CI}=1.39-30.44$ )

Breast was the commonest site of primary lesion in the study group $(18,51 \%)$, followed by lung $(12,34 \%)$. Primary could not be located in one case, with malignancy proved in supra clavicular lymph node biopsy. Adenocarcinoma was the most common histopathology $(22,69 \%)$.

Except for one case of Phylloides tumour, the other 17 of carcinoma breast subgroup were invasive ductal carcinoma. Immunohistochemistry report was available for 12 of them of which 5 were triple (ER PR HER2) negative, 4 triple positive and 3 ERPR negative with HER2 positive. All 3 patients with HER2 alone positive had visceral metastasis, and brain metastasis was late to occur than visceral. The most common stage at diagnosis of primary is stage $4(20,57 \%)$. Breast carcinoma patients have 6 times more chance (odds ratio $-5.88, \mathrm{CI}-1.39-28.45$ ) of having visceral spread before or along with onset of brain metastasis compared to exclusive brain spread (Table 2).

In the 12 patients with lung primary, 5 (42\%) were adenocarcinoma as against $3(25 \%)$ squamous cell carcinoma. 9(75\%) in the subset had exclusive brain metastasis with no other visceral spread. A patient with lung metastasis has 4 times chance of having exclusive brain spread than having visceral and brain metastasis. 11 of 12 were stage four at first presentation itself. 4 out of 12 were female (non-smokers). Lung is the commonest primary site in patients with exclusive brain metastasis 20 $(57 \%)$ of 35 patients were at stage 4 at initial diagnosis itself. Majority of them had lung primary $(11,55 \%)$ followed by breast primary $(6$, $30 \%) .70 \%(\#=14)$ of the stage 4 patients had synchronous detection of brain metastasis along with primary lesion, of which majority $(11,79 \%)$ had lung primary (Table 3). The other $30 \%$ had visceral metastasis at presentation with metastasis to brain occurring at a later date.

The time period from onset of primary (malignancy) to occurrence of metastasis (PFS) was <1 year in majority of patients $(28,80 \%)$, range being 0 to 60 months.

\section{Discussion}

Cancer remains a disease yet to be conquered by man, in spite of all medical and surgical advancements, technological innovations and various researches. When the malignancy spreads to other organs of the body, the prognosis becomes worse, more so when the spread is to the brain. The incidence of brain metastasis varies between $9-19 \%$ as per Lakshmi Nayak et al ${ }^{[1]}$ and Barnholtz-Sloan et $\mathrm{al}^{[2]}$. This is increasing with better diagnostic modalities and better treatment of primary leading to prolongation of overall survival.

Table 2: Factors associated with having multiple metastatic lesions in the brain among patients admitted with brain metastasis in Radiation Oncology Department, Royapettah hospital, Kilpauk Medical College, Chennai 2013-18:

\begin{tabular}{|c|c|c|c|c|c|}
\hline Characteristics & Description & Multiple lesions & Single or 2 lesions & Odds & CI \\
\hline \multirow{2}{*}{ Old Age } & $>60$ & 3 & 6 & \multirow{2}{*}{0.59} & \multirow{2}{*}{$0.10-2.93$} \\
\hline & $\leq 60$ & 12 & 14 & & \\
\hline \multirow{2}{*}{ Visceral metastatis } & Yes & 11 & 6 & \multirow{2}{*}{6.04} & \multirow{2}{*}{$1.39-30.44$} \\
\hline & No & 4 & 14 & & \\
\hline \multirow{2}{*}{ Breast primary } & Yes & 9 & 9 & \multirow{2}{*}{1.48} & \multirow{2}{*}{$0.36-6.29$} \\
\hline & No & 6 & 9 & & \\
\hline \multirow{2}{*}{ Lung primary } & Yes & 4 & 8 & \multirow{2}{*}{0.55} & \multirow{2}{*}{$0.12-2.39$} \\
\hline & No & 11 & 12 & & \\
\hline
\end{tabular}


Table 3: Association between primary site of the cancer with involvement of exclusive brain metastasis among patients admitted with brain metastasis in Radiation Oncology Department, Royapettah hospital, Kilpauk Medical College, Chennai 2013-18:

\begin{tabular}{|l|c|c|c|c|c|}
\hline Characteristics & Description & Exclusive Brain & Other visceral involvement & Odds & CI \\
\hline \multirow{2}{*}{ Lung primary } & Lung primary & 9 & 3 & \multirow{2}{*}{4.47} & \multirow{2}{*}{$0.97-25.35$} \\
\cline { 2 - 6 } & Others & 9 & 14 & \multirow{2}{*}{5.88} & \multirow{2}{*}{$1.39-28.45$} \\
\cline { 2 - 7 } Breast primary & Others & 12 & 5 & 13 & \\
\cline { 2 - 7 } & Breast primary & 5 & &
\end{tabular}

As per Seoane $\mathrm{J}$ and De Mattos-Arruda $\mathrm{L}^{[3]}$, cells that metastasise to brain have unique molecular signature compared to other cells in the same tumour. Brain metastasis also depends on these cells' interaction with blood brain barrier, local immune system and glial cells and also upon vascular endothelial growth factor helping in neovascularisation.

All cases of metastasis brain cannot be brought under one umbrella. According to Pérez-Larraya $\mathrm{JG}$ et $\mathrm{al}^{[4]}$,prognosis depends on age, extent and activity of the systemic disease, number of brain metastases and performance status. They vary with the organ where the primary originates, its histopathology, immune-histochemistry. In this study we have analysed the afore said variables in our study group attempting to throw some light on susceptibility to metastasis to brain. Contrary to the findings of Saha $\mathrm{A}$ et $\mathrm{al}^{[5]}$ and Fabi $\mathrm{A}$ et $\mathrm{al}^{[6]}$ that brain metastasis was common in fifth and sixth decade of age, we found our patients to be younger. This is of much concern to the society as it affects the productivity during the illness and affects the dependants after their early demise. This also throws light on importance of cancer screening protocol to start at younger age itself in high risk population.

Any patient on treatment for any systemic malignancy should be evaluated with CT brain if he develops headache, as about half of the patients in this group presented with headache only, similar to that reported by Singh $\mathrm{S}$ et $\mathrm{al}^{[7]}$. Neurological symptoms like seizures and hemiparesis are often due to the perilesional oedema rather than the lesion itself and may show significant though transient improvement with anti-oedema measures

MRI brain remains the gold standard for detecting brain metastasis in patients with symptoms. According to Bochev $\mathrm{P}$ et $\mathrm{al}^{[8]}$, including brain in whole body FDG PET CT scan in staging workup can pick up asymptomatic metastasis brain, though it is less sensitive and lesions were found only in $1 \%$ of screened patients. This is similar to what we noticed in two patients who underwent staging PET, revealing brain lesions even while asymptomatic. Further studies are required to validate the inclusion of brain screening routinely in staging the disease.

Multiple metastasis brain may be considered as an indicator of disseminated disease, as evidenced by the strong association of multiple brain metastasis and spread to many other viscera / bones. Early diagnosis of primary lesion before onset of metastasis and appropriate management (surgical, radiotherapy and chemotherapy) does not prevent dissemination to brain and other organs but does delay the occurrence (prolonged progression free survival time). According to Nussbaum ES et $\mathrm{al}^{[9]}$ the median duration from diagnosis to presentation with a brain metastasis was 12 months, ranging from 3 months to 53 months. In our study also majority of patients presented with brain metastasis within 12 months of diagnosis of primary tumour.

In majority of studies including Saha et $\mathrm{al}^{[5]}$ and Singh $\mathrm{S}$ et $\mathrm{al}^{[7]}$, lung was the commonest primary disseminating to brain followed by breast. But in our study the number of patients with breast tumour outnumbered that with lung. This might be due to the large number of breast cancer patients 
operated in our hospital surgery and surgical oncology units and kept under constant follow up. However, Lung primary is the most common silent primary presenting in advanced metastatic, disseminated state, in our study similar to that reported by Cagney DN et $\mathrm{al}^{[10]}$. This negates the option of any curative management with very poor prognosis and throws light on the need for a screening method for lung malignancy in the highrisk group.

As per latest guidelines for non-small cell lung cancer, in pre-treatment staging workup, from stage 2, CT/MRI brain is to be done, even in patients with no neurological symptoms. In our study it was observed that lung cancer patients have 4 times more chance of having exclusive brain metastasis with no visceral or bone spread.

\section{Conclusion}

1) Breast and lung are leading in cancers which spread to brain, among which lung primary is commoner in patients with exclusive metastasis to brain

2) Majority of patients with lung primary present in late stage, with disseminated disease status.

\section{Conflicts of interest - Nil \\ Disclosure / disclaimer- Nil \\ Financial support: Nil}

\section{References}

1. Nayak, L., Lee, E.Q. \& Wen, P.Y. Curr Oncol Rep (2012) 14: 48. https://doi.org/10.1007/s11912-011-0203$\mathrm{y}$

2. Barnholtz-Sloan, J. S., Sloan, A. E., Davis, F. G., Vigneau, F. D., Lai, P., \& Sawaya, R. E. (2004). Incidence Proportions of Brain Metastases in Patients Diagnosed (1973 to 2001) in the Metropolitan Detroit Cancer Surveillance System. Journal of clinical oncology, 22(14), 2865-2872. doi: 10.1200/jco.2004.12.149
3. Seoanea, Joan and De Mattos-Arrudaa, Leticia, (2014), Brain metastasis: New opportunities to tackle therapeutic resistance, Molecular Oncology, 8, doi: 10.1016/j.molonc.2014.05.009.

4. Pérez-Larraya JG, Hildebrand J. Brain metastases. In Handbook of Clinical Neurology 2014 Jan 1 (Vol. 121, pp. 11431157). Elsevier. https://doi.org/ 10.1016/B978-0-7020-4088-7.00077-8

5. Saha, A., Ghosh, S. K., Roy, C., Choudhury, K. B., Chakrabarty, B., \& Sarkar, R. (2013). Demographic and clinical profile of patients with brain metastases: A retrospective study. Asian journal of neurosurgery, 8(3), 157-161. doi:10.4103/1793-5482.121688.

6. Fabi A, Felici A, Metro G, Mirri A, Bria E, Telera S, Moscetti L, Russillo M, Lanzetta G, Mansueto G, Pace A. Brain metastases from solid tumors: disease outcome according to type of treatment and therapeutic resources of the treating center. Journal of Experimental \& Clinical Cancer Research. 2011 Dec;30(1):10.

7. Singh S, Amirtham U, Premalata CS, Lakshmaiah KC, Viswanath L, Kumar RV. Spectrum of metastatic neoplasms of the brain: A clinicopathological study in a tertiary care cancer centre. Neurol India [serial online] 2018 [cited 2019 Jul 19];66:733-8. Available from: http:// www.neurologyindia.com/ text.asp?2018/66/3/ 733/ 232333

8. Bochev P, Klisarova A, Kaprelyan A, Chaushev B, Dancheva Z. Brain metastases detectability of routine whole body (18)F-FDG PET and low dose CT scanning in 2502 asymptomatic patients with solid extracranial tumors. Hell J Nucl Med. 2012 May-Aug;15(2) 125-129. doi:10.1967/s002449910030. PMID: 22741148.

9. Nussbaum, E. S., Djalilian, H. R., Cho, K. H. and Hall, W. A. (1996), Brain 
metastases: Histology, multiplicity, surgery, and survival. Cancer, 78: 17811788 doi:10.1002/(SICI)10970142(19961015)78:8<1781::AID-

CNCR19>3.0.CO;2-U.

10. Daniel N Cagney, Allison M Martin, Paul J Catalano, Amanda J Redig, Nancy U Lin, Eudocia Q Lee, Patrick Y Wen, Ian F Dunn, Wenya Linda Bi, Stephanie E Weiss, Daphne A Haas-Kogan, Brian M Alexander, Ayal A Aizer, Incidence and prognosis of patients with brain metastases at diagnosis of systemic malignancy: a population-based study, Neuro-Oncology, Volume 19, Issue 11, November 2017, Pages 1511-1521, https://doi.org/10.1093/neuonc/nox077. 